\title{
The Role of Trust in Social Entrepreneurship:
}

\author{
A Case Study of Global Brigades
}

Laura Tack

Mark Simon

Ruihua Joy Jiang

ocial entrepreneurship literature acknowledges that social
capital is vital to the success of social entrepreneurship efforts and trust is integral to the process of building social capital. However, there has been limited research on trust itself in social entrepreneurship literature. This article aims to begin filling this gap by utilizing a specific social entrepreneurship initiative to illustrate the role of trust in social entrepreneurship efforts. It describes the model of trust developed by Sheppard and Sherman and the social entrepreneurship initiative, Global Brigades. The article discusses the relationships between the parties involved in the initiative and applies Sheppard and Sherman's model to these relationships. It illustrates the importance of trust to social entrepreneurship efforts, as well as the need for additional research regarding social entrepreneurship and trust.

Keywords: social entrepreneurship; trust; international social entrepreneurship; case study; indigenous people; poverty

Social entrepreneurship has generated much interest in the private, public, and not-for-profit sectors (Jiao, 2011). Although there are many definitions for this concept (Jiao, 2011), social entrepreneurship can broadly be described as "a process involving the innovative use and combination of resources to pursue opportunities to catalyze social change and/or address social needs" (Mair \& Marti, 2006, p. 37). Many variables determine the success of a social entrepreneurship initiative. One such variable is social capital, which is prominently addressed in social entrepreneurship literature. Social capital is the "actual and potential assets embedded in relationships among individuals, communities, networks, and societies" (Mair \& Marti, 2006, p. 41). Social capital includes access to resources, information, and support; trust; respect; and friendliness (Mair \& Marti, 2006).

It is well established in social entrepreneurship literature that social capital is vital to the success of social entrepreneurship efforts. Jiao's (2011) conceptual model for social entrepreneurship indicates that social capital is positively related to both the creation and survival of social entrepreneurship initiatives. Mair and Marti (2006) state that social capital helps social entrepreneurs relieve social problems and enter the public sphere. Scheiber (2014) finds that social capital allows social entrepreneurs to develop a better understanding of complex social problems, which results in more effective social entrepreneurship initiatives.

Entrepreneurship literature acknowledges that trust is integral to the process of building social capital (Bogren \& von Friedrichs, 2016; Zhang \& Hamilton, 2010). However, social entrepreneurship literature largely neglects the analysis of trust itself (Curtis, Herbst, \& Gumkovska, 2010). This is not due to lack of relevance; trust is undeniably important in social entrepreneurship efforts. Trust facilitates cooperative behavior, decreases detrimental conflict, reduces transaction costs, promotes network relations, enables swift formulation of ad hoc work groups, and promotes effective responses to crises (Rousseau, Sitkin, Burt, \& Camerer, 1998); all of which are critical in social entrepreneurship efforts. Scheiber's (2014) analysis of 27 social entrepreneurs in Rio de Janeiro found trust to be instrumental in increasing participation in social entrepreneurship initiatives, gaining access to additional members of the target population, and achieving greater levels of effectiveness and social impact. Nevertheless, very little existing social entrepreneurship literature explicitly focuses on trust.

This article aims to begin filling this gap by utilizing a specific social entrepreneurship initiative to illustrate the necessity of trust in social entrepreneurship efforts. The article begins with a description of the model of trust developed by Sheppard and Sherman (1998). It then describes the social entrepreneurship initiative, Global Brigades. The article next discusses the relationships between the parties involved in the initiative and applies Sheppard and Sherman's model to these relationships. The discussion that concludes this article illustrates the importance of trust to social entrepreneurship efforts, as well as the need for additional research regarding social entrepreneurship and trust. 
The initial research for this case study was completed by two of the authors as they participated in a social entrepreneurship initiative organized by Global Business Brigades, a program dedicated to creating and sustaining economic empowerment within impoverished communities in various third-world countries. As participants in the brigade, the authors spent a week providing financial literacy workshops and individualized business consultation in the village of Ipeti Emberá, Panama. This experience gave the authors valuable firsthand knowledge of the parties involved in this social entrepreneurship initiative, as well as the relationships and forms of trust between these parties.

\section{The Grammars of Trust and the Corresponding Model}

Sheppard and Sherman (1998) argue that trust can be understood as four separate and ordered forms determined by two dimensions of a given relationship: relational form and relational depth. These four forms, which are informed by Fiske's (1990) four elemental forms of human relationships, are shallow dependence, deep dependence, shallow interdependence, and deep interdependence (Sheppard \& Sherman, 1998).

Shallow dependence is characterized by a unidirectional dependency and limited, often shortterm, relational depth (Sheppard \& Sherman, 1998). One example of shallow dependence is the relationship between a shopper and an online clothing store. The main risks associated with shallow dependence are (1) unreliability, which is the risk that one party will not behave as expected and (2) indiscretion, which is the risk that one party will inappropriately utilize or disclose sensitive information (Sheppard \& Sherman, 1998). Sheppard and Sherman (1998) contend that the appropriate mechanism to produce trust in a shallow dependence relationship is deterrence based. This mechanism may involve penalties imposed on parties that perform unreliably or counter to the agreement, or costs of discontinuing the partnership that outweigh the benefits of acting in a distrustful manner (Sheppard \& Sherman, 1998).

Deep dependence describes a relationship with intensive, often long-lasting, relational depth in which the trustee's behavior is outside the trustor purview and consequently challenging to monitor (Sheppard \& Sherman, 1998). An example of a deep dependence relationship is the relationship between a boss and an employee. The risks associated with deep dependence include the aforementioned risks as well as (1) cheating, which is when one party utilizes information asymmetry to the dependent party's disadvantage; (2) neglect, which involves the omission of one party's interests; (3) abuse, which occurs when one party uses its ability to determine the fate of a second party to impose additional costs; and (4) self-esteem, which can occur when one party's sense of self is directly related to the deep relationship (Sheppard \& Sherman, 1998). The appropriate trust mechanism to use in deep dependence relationships is the evocation of a sense of obligation (Sheppard \& Sherman, 1998).

Shallow interdependence describes a relationship with limited, often short-term, relational depth in which the achievement of desired goals depends on effective coordination between parties (Sheppard \& Sherman, 1998). One example of shallow interdependence is the relationship between members of a short-term project team. The risks associated with shallow interdependence are unreliability; indiscretion; and poor coordination, which is the risk that coordination will not be rapid or effective enough to be successful (Sheppard \& Sherman, 1998). The appropriate trust production mechanism in shallow interdependence relationships is "active discovery through communication and research" (Sheppard \& Sherman, 1998).

The fourth form is deep interdependence, which is characterized by intense, often long-term, relational depth and interdependent parties (Sheppard \& Sherman, 1998). An example of deep interdependence is the relationship between husband and wife. Deep interdependence is subject to all of the aforementioned risks as well as misanticipation, which is the risk that without detailed instructions, one party will be unable to anticipate the needs or actions of the other party (Sheppard \& Sherman, 1998). The necessary trust mechanism in deep interdependence relationships is internalization, which occurs when each party adopts the other party's beliefs and preferences (Sheppard \& Sherman, 1998).

The model developed by Sheppard and Sherman (1998), summarized in Table 1, is useful in understanding the production of trust in multiple types of social entrepreneurship relationships. This article utilizes a case study of Global Brigades, an international nonprofit organization, to consider these forms of trust in the context of a contemporary social entrepreneurship initiative. As discussed below, Global Brigades is a nonprofit organization that empowers small, impoverished

46 NEW ENGLAND JOURNAL OF ENTREPRENEURSHIP 
Table 1. Summary of Relevant Components of Sheppard and Sherman's Model of Trust

Form of Dependence

Shallow dependence

$\begin{array}{cc} & \text { Cheating } \\ \text { Deep sependence } & \text { Neglect } \\ \text { Abuse } & \text { Self-esteem }\end{array}$
Risks

Unreliability

Indescretion
Mechanism for Trust

Deterrence
Relationship Example

Shopper and online clothing store

\begin{tabular}{|c|c|c|c|}
\hline Deep sependence & $\begin{array}{c}\text { Cheating } \\
\text { Neglect } \\
\text { Abuse } \\
\text { Self-esteem }\end{array}$ & Obligation & Boss and employee \\
\hline Shallow interdependence & Poor coordination & Discovery & $\begin{array}{c}\text { Members of short-term } \\
\text { project team }\end{array}$ \\
\hline Deep interdependence & Misanticipation & Internalization & Husband and wife \\
\hline
\end{tabular}

communities to gain medical, financial, and environmental self-sufficiency. The work of Global Brigades in the Panamanian village of Ipeti Emberá provides a very interesting platform for the discussion of Sheppard and Sherman's (1998) forms of trust and social entrepreneurship for two reasons. First, Ipeti Emberá simultaneously maintains three relationships: one with the national government, one with Global Brigades, and one with student volunteers. Second, due to Global Brigades regulations, the relationship between the village and the organization is very different from the relationship between the village and the student volunteers. As a result, these three relationships allow three distinct forms of trust to be observed in just one case study. Because this case provides insight into three of the four forms of trust, the findings of this article can be adapted and applied to many social entrepreneurship initiatives, even when situational details vary.

This article will discuss each relationship and the resulting form of trust. Namely, we will discuss deep dependence in regards to the village and the national government, deep interdependence in regards to the village and Global Brigades, and shallow interdependence in regards to the village and student volunteers. These three forms of trust are particularly relevant to social entrepreneurship initiatives. First, deep dependence is relevant to social entrepreneurship because the need for social entrepreneurship is often created by the failure of a deep dependence relationship, such as the relationship between a community and its government. Second, deep interdependence is relevant to social entrepreneurship because social entrepreneurs often invest significant resources into the initiatives, and the target populations rely on the resulting assistance. Finally, shallow interdependence is relevant to social entrepreneurship initiatives because such initiatives often involve individuals who participate without fully internalizing the social entrepreneur's dedication or investments; this can produce a shallow interdependence relationship between these individuals and the target population.

The fourth form of trust, shallow dependence, is not present in this case study. The intensive nature of Global Brigades prevents such a relationship from forming; the brigades are week-long immersive experiences, and the student volunteers are responsible for funding their own travel and accommodation expenses. As a result, the students are both financially and emotionally invested in their brigade; they rely on the villagers' participation and cooperation to achieve the satisfaction of having a successful brigade, just as the villagers rely on the students' efforts. This situation is, as we will discuss later in this article, not unusual. Social entrepreneurship initiatives rarely result in shallow dependence relationships because both parties are often invested in the outcome, and must rely on each other to achieve success. 


\section{The Social Entrepreneurship Initiative: Global Brigades}

Global Brigades is an "international non-profit that empowers communities to meet their health and economic goals through university volunteers and local teams" (Global Brigades, 2015d). The organization identifies impoverished villages within poverty-stricken nations and determines the specific needs of each community. These needs may be medical, architectural, entrepreneurial, etc. Global Brigades then mobilizes students and professors from universities around the world, sending them on week-long trips to these communities. Each trip, or "brigade," is customized to provide for the community's specific needs. The students, also known as "brigaders," are encouraged to join brigades that utilize their skill sets and education. For example, a brigade comprised of medical students and professors would be sent to a community requiring medical assistance.

\section{History}

Global Brigades traces its roots to 2003, when a lone medical brigade travelled to Honduras (Global Brigades, 2015a). The brigade was mainly comprised of students and doctors from the Midwest United States who spent their time in Honduras providing medical care to members of rural communities (Global Brigades, 2015a). Later in 2003, one of the original brigade members helped found Global Medical Relief, Inc., working with American medical students to bring good, sustainable medical care to rural communities in developing countries (Global Brigades, 2015a). Global Medical Relief, Inc. was disbanded in 2005, but one of the original Honduras brigade members continued its mission through a new organization entitled Global Medical Brigades (Global Brigades, 2015a). The growth of Global Medical Brigades led to the inception of Global Brigades, Inc., a nonprofit corporation headquartered in the United States. Like its predecessors, Global Brigades utilized student volunteers to provide medical services to impoverished communities in Honduras. As the organization grew, the medical brigades noted additional needs within the communities they were serving, and expanded to include Business, Water, Public Health, Microfinance, Environmental, Architecture, and Law Brigades throughout 2007 and 2008 (Global Brigades, 2015a). During the following years, Global Brigades welcomed universities from multiple countries and began serving additional impoverished nations.
Today, Global Brigades is comprised of multiple independent legal entities, each of which is a member of the Global Brigades Association (Global Brigades, 2015b). These entities are based in the United States, Canada, Germany, Switzerland, Ireland, the United Kingdom, Ghana, Honduras, Panama, and Nicaragua (Global Brigades, 2015b). Within the Global Brigades Association, each entity has equal representation as a member of the Board of Directors (Global Brigades, 2015b).

\section{Business Model}

As Global Brigades grew, it recognized the need for its "holistic model," which ensures each brigade complements the others (Global Brigades, 2015a). For example, a Water Brigade may help a community install a clean water supply in response to a Medical Brigade's indication of such a need. The holistic model also includes a clear exit strategy to be executed once a community becomes sustainably self-sufficient (Global Brigades, 2015a). Global Brigades has also implemented organization-wide best practices and designed universal marketing kits to streamline the creation of additional Global Brigades chapters (Global Brigades, 2015a).

As one of the largest student-led volunteer relief organizations in the world, Global Brigades receives the vast majority of its income from the volunteers themselves. In the months leading up to a brigade, each brigader is responsible for financing brigade expenses in advance. The revenue received from brigaders themselves is supplemented by contributions from organizations and individuals who would like to finance specific Global Brigade projects, as well as the organization's overhead expenses.

\section{The Relationships within the Social Entrepreneurship Initiative Ipeti Emberá and the Panamanian Government}

The village visited by the authors, Ipeti Emberá, is a rural community comprised of approximately 85 families. Its inhabitants are members of the Emberá ethnic group. This indigenous group is one of the largest in Panama, but constitutes only 0.9 percent of the country's population (Central Intelligence Agency, 2015). Unlike the mestizo (mixed indigenous and white) population in Panama that generally embraces contemporary Hispanic culture, the indigenous population of Panama-composed of multiple distinct and unique ethnicities, including the Ngabe, Kuna, Emberá, and Bugle people-tends to place a much stronger emphasis on the history and culture of their respective tribes (Central Intelligence Agency, 2015). 
Due to these and other complex societal and historical reasons, relations in Panama between the mestizo population and indigenous communities are strained, and the nation's indigenous people are often treated as second-class citizens. As a result, while the non-indigenous rural poor have had some success in escaping poverty by migrating to urban areas, the indigenous populations constitute an increasing portion of the nation's poor and extreme poor (Central Intelligence Agency, 2015). Panama has the second worst income distribution in Latin America, and government attempts to alleviate poverty and inequality have been largely ineffective (Central Intelligence Agency, 2015).

The poverty statistics for the village of Ipeti Emberá are not known because a high illiteracy rate and lack of financial education preclude many members from recording their income. However, it is reasonable to assume the community's poverty level closely resembles official statistics, which state 96.7 percent of Panama's indigenous population falls below the poverty level of \$3.13 per day (Global Brigades, 2014).

The community's government follows a general policy of autonomy and separation from the outside world and the Panamanian government allows the community to conduct its own affairs with very little assistance or interference. This occurs for many reasons. The most significant reason for the separation between the village and the government is the cultural differences and friction, described above, between the mestizo population and the indigenous population. However, observed lack of assistance has further embittered villagers against the government. For example, the government once promised to send agriculture experts to the village to assist and instruct the agrarian community. The visit was supposed to last for many days, but the experts arrived and left within one hour. In addition, the teachers in government-funded schools teach in Spanish, a second language to the children of Ipeti Emberá. These children do not receive additional assistance or instruction due to the language barrier; instead, they are marginalized and often fall behind as a result. Another example involves the infrastructure surrounding Ipeti Emberá. Due to its close proximity to the Columbian border, the Panamanian government intentionally leaves the region's roads in disrepair to hinder drug smugglers who may attempt to escape pursuing police. Due to the lack of support provided by the Panamanian government, the vast majority of community problems are solved within Ipeti Emberá without assistance from individuals or institutions outside of the village (Global Brigades, 2015c).

\section{Ipeti Emberá and Global Brigades}

Global Brigades spends ample time initially evaluating a community and its needs before initiating brigades to that community. First, Global Brigades communicates with the community to determine if it is needful of and receptive to external assistance. Then Global Brigades works with the community to assess which type of assistance-medical, dental, business, etc. - would be most beneficial to the community. Once the community and Global Brigades have agreed on a program, the Global Brigade initiatives can begin.

Each community typically receives two week-long brigades each year. These are supplemented by in-country Global Brigades staff members who establish weekly communication with each community. In this way, Global Brigades can provide ongoing support to a community until it becomes self-sufficient. Self-sufficiency is accomplished in a unique way for each aspect of life. Concerning water, self-sufficiency may mean that the community is capable of maintaining its own clean water system. In a business sense, self-sufficiency may be achieved when the community is knowledgeable enough to make informed financial decisions and able to run its own community cooperative. Once a community is self-sufficient, Global Brigades ceases to send brigades and offers only minimal support.

The authors of this article took part in a Global Business Brigade (GBB), a subset of Global Brigades designed to help communities in an economic capacity. GBB utilizes three tools to improve the economic standing of communities such as Ipeti Emberá: credit and savings cooperatives, financial literacy workshops, and personalized business development and consulting.

Credit and Savings Cooperative. GBB helps each community establish a Credit and Savings Cooperative. GBB provides the initial start-up capital and teaches elected leaders of the cooperative how to manage the operation. These cooperatives, which are essentially banks run by the community, introduce much-needed investment capital into the community and enable small businesses and individuals in the community to take out loans. Any profits from the loan operations are reinvested in the community. At the time of the authors' brigade, the Ipeti Emberá cooperative had 21 members and 7 outstanding loans totaling approximately $\$ 265$. Although the interest from the loans was simply increasing the cooperative's capital at the time of the brigade, cooperative members expressed a desire to use the interest income to purchase a community vehicle at some point in the future. 
The Credit and Savings Cooperative also entices members to save their money by offering an interest rate of 1 percent per month. As a culture, the indigenous people of Panama do not embrace the concept of saving. The prevailing wisdom is a type of monetary carpe diem: you don't know when you'll have money again, so you better spend it while you have it. Combatting this ingrained way of thinking and encouraging villagers to save is one of GBB's main goals.

Financial Literacy Workshops. GBB has outlined a series of financial literacy topics to teach community members how to make financial goals, create budgets, save money, plan for financial emergencies, and obtain loans. This curriculum is designed to be taught, bit by bit, by multiple brigades. In each community, wherever in the curriculum one brigade ends, the next brigade begins. At the time of the authors' brigade, the community members had only been exposed to the first portion of the curriculum, which included making financial goals and examining spending habits. The education in Ipeti Emberá outside of these financial literacy workshops is minimal due to a lack of resources. Many community members strive to provide their children with a better education than they themselves had access to; few individuals within the community have more than an elementary-level education, and approximately 50 percent of the community's population is illiterate (Global Brigades, 2015c).

\section{Personalized Business Development and Consultation.}

GBB enables brigade members to provide business development and consulting to entrepreneurs who have been previously identified by and worked with GBB. A business brigade is divided into smaller teams, each of which is responsible for providing business consultation to a small business within the community. Just as multiple brigades will come to the same community to teach financial literacy workshops, each small business will receive guidance from multiple small teams. In Ipeti Emberá, essentially every community member is selfemployed, as agriculture and craft-making work employs most of the villagers. The more advanced entrepreneurial efforts within Ipeti Emberá include a few pig farms and six small kiosks owned by individuals who sell consumer goods such as snacks, soda, and trinkets.

\section{Ipeti Emberá and the Authors' Team}

Two key facts should be initially noted. First, each community receives brigades from chapters around the world; it is extremely rare for a chapter to visit the same community more than once. As a result, each brigade will be the first interaction between the community and the individual brigade members, but not the first interaction between the community and Global Brigades. Second, it is very difficult for brigade members to contact community members after they have left the country. This restriction in communication has both practical and regulatory causes. The former concerns the difficulty of reaching community members, as very few of them have access to contemporary communication tools. The latter relates to the Global Brigades policy itself; Global Brigades discourages communication between the community and previous brigades due to negative past experiences. In previous years, Global Brigades allowed brigaders to contact villagers after they had completed their brigade. However, while most brigaders promised to remain dedicated to the community until the villagers' difficulties were mitigated, very few students kept their promise. Most students returned home and became too involved in their own lives and responsibilities to continue communicating with community members. The villagers felt abandoned, and they often blamed Global Brigades. As a result, Global Brigades has implemented policies that enable it to be the sole point of contact for all brigade-related matters the community members may wish to discuss.

The authors (one student and one professor) took part in a brigade consisting of 12 business students, 2 business professors, 3 students majoring in Spanish, and 2 Global Brigades employees. One Global Brigades employee served as a translator and the other, Kevin, served as a translator, guide, and overall liaison between the brigaders and villagers. The brigade was split into three teams. Each team had two distinct responsibilities: financial literacy education and small business consultation.

Before the brigades went to the community for the first time, Kevin gave a presentation that highlighted the cultural differences between the American brigaders and the Ipeti Emberá villagers. First, while the majority of the students spoke only English, the community members spoke a mix of Spanish and Emberá. Second, although the students were anxious to get started, the community members felt no need to hurry. The presentation encouraged the brigaders to be both patient and flexible, as the community members did not want to move nearly as quickly as their American visitors. Third, the presentation stressed the pride the villagers had in their culture. This point was reinforced time and time again once the brigaders met the villagers.

50 NEW ENGLAND JOURNAL OF ENTREPRENEURSHIP 
During the initial meeting between community members and brigaders, the village leader illustrated multiple traditions that were maintained for purely cultural reasons. For example, the Emberá people had lived by rivers and other sources of water for centuries, and had learned to raise their buildings on stilts to protect them from potential flooding. Even though the Ipeti Emberá community was on ground high enough to provide protection from all but the most severe flooding, the community continued to build its structures on stilts to preserve this cultural tradition. Additionally, almost all adults in the community, men and women alike, took great pride in creating traditional Emberá crafts. The women typically made jewelry and embroidered, while the men carved wood. Women in the community had even created an artisan group that sold their crafts to tourists. Due to the dearth of visitors, members of the artisan group were overstocked, but they continued to travel to Panama City once a month to buy supplies to make additional crafts because they refused to neglect this aspect of Ipeti Emberá tradition.

Financial Literacy Workshops. As described above, GBB outlined a series of topics designed to increase financial literacy within the community. Students within the brigades were responsible for developing lessons for each of their designated topics and deciding how best to present these lessons to community members. During the lessons, the GBB staff members served only as translators, offering minimal input. Aside from adhering to various cultural mores, there was only one recommendation the brigaders were strongly encouraged to follow: begin each lesson with an icebreaker. Icebreakers could essentially be anything, as long as they were designed to establish trust and rapport between the brigaders and the community members. To further develop camaraderie between the students and villagers, GBB implemented a "best friend" component of the financial literacy workshops. At the beginning of a brigade, each community member chose a student to be their "best friend."Throughout the rest of the week, each brigader was responsible for ensuring, as much as possible considering the language barrier, that his or her best friend was following along and understanding the concepts presented in the workshops.

The authors' team began each financial literacy workshop with an icebreaker. One icebreaker progressed as follows: an imaginary line down the middle of the floor divided a "yes" side from a "no" side. Kevin made a statement about anything he wished, and all the participants - brigaders and villagers - moved to the side of the floor that responded to the statement properly for them. Simple statements (e.g., "I like to sing" and "I don't like spicy food") helped both brigaders and villagers realize that each one of them was an individual with preferences and desires that could not be dictated by country and culture. By drawing a line and asking participants to consistently cross it, the divide between brigaders and villagers diminished. Even when certain cultural differences showed themselves (e.g., a desire of the female villagers to cook and raise children that was not shared by their American counterparts), the differences were intriguing instead of alienating. By the end, brigaders and villagers were suggesting statements and laughing with each other at the sometimes unexpected results.

As the workshops progressed, the brigaders never ceased to be amazed by the villagers' willingness and ability to learn. The villagers were excited to understand the brigaders'financial advice and apply the guidance to their own lives. A prime example of this occurred when the brigaders warned against making impulsive purchases. They recommended creating a shopping list before going to the store or community kiosk and taking only the amount of money necessary to purchase items on the list. The next day, a woman in the group described her trip to one of the town's kiosks. She had seen a lovely hair clip but only had enough money with her to buy food, as recommended in the workshop. She was consequently unable to buy the clip. When she returned home and considered going back to purchase the accessory, she realized she owned a clip that was almost identical to the one in the kiosk. She was understandably relieved that the advice from the workshop prevented her from wasting money that was better spent on provisions for her family. The ability to absorb and apply concepts exemplified by this woman was shared among almost all of the members of the workshop, and was an encouragement to both brigaders and villagers.

Personalized Business Development and Consultation. Each afternoon following the financial literacy workshops, the teams spent time advising their respective business owners. The authors were on a team of six assigned to work with Melania Sarco, the owner of a pig farm named Cría de Melania. The team assigned to Melania's business had received some background information before the brigade, but their knowledge of Cría de Melania was minimal. While the team had hoped to gain knowledge 
from Melania during the workshops, this was not possible because Melania was in a different team's workshop group. Additionally, Melania's "best friend" was not in the business consultation team, so the team was not able to get to know her in that regard. Kevin served as the translator for the team because he had worked with Melania earlier in the year alongside a different university. Nevertheless, he had shared little of his prior knowledge of Melania's case; he did not want past experiences to dictate present actions.

The meetings with Melania took place in her home. During the first meeting, the team committed many cultural gaffes that undermined its members'relationship with Melania. For example, when the team went to meet Melania for the first time, they saw that her home was a hut on stilts with a thatched roof. Except for a blue tarp that formed one outer wall of the house, the structure had no walls. Because of this, the team was able to see Melania sitting inside when they reached the hut. The students and professor waved and climbed up the notched log leaning against the side, which served as a ladder. The team later learned that proper etiquette demanded calling out to, and being acknowledged by, the home's inhabitants before climbing up the log ladder. This process was essentially equivalent to ringing a doorbell before entering a house. The team members also inadvertently neglected to remove their shoes upon entering the domicile, which was a sign of disrespect. Additionally, the excited team immediately jumped into rapid-fire questions about Melania and her business, forgetting the cultural norm of getting to know new acquaintances on a personal level before discussing practical matters. Even worse, the team's first question, which was designed to help the team gauge Melania's abilities, concerned her level of education and whether she was literate. Because Melania was illiterate, this well-intentioned question seemed condescending and intrusive.

During their meeting, Melania explained that she had lived in Ipeti Emberá her entire life and had received her knowledge of pig farming from her mentor, Lucia, who had been raising pigs for years. GBB had offered to give Lucia business consulting services just as Melania was receiving, but she had refused. In addition to the knowledge she gained from Lucia, Melania had some personal experience raising pigs. She started her pig farm two years before with the hope of generating additional income to provide basic necessities for her family. She had previously raised a pig until it grew to be 300 pounds. Her husband, Ariel, sold the pig without consulting Melania or her children. Because Ariel was unfamiliar with the pig market, he did not realize a fair price for the pig was approximately $\$ 675$, and consequently sold the pig for $\$ 125$. This unfortunate sale represented a huge setback for Melania. Because she had invested so much money in her first pig, she did not have much additional capital to invest in the business. She had since managed to buy another pig, but her limited resources prevented her from feeding it properly, which drastically impaired its ability to gain weight. Additionally, because she also worked in agriculture and made artisan crafts to sell to tourists, the time she had to devote to the pig farm was minimal.

Through many questions and much translation, the team continued to learn more about Melania's business. Kevin suggested Melania take the team to see the pig pen, and the team readily accepted. The pen itself consisted of a concrete slab on the ground fenced in by wooden slats. Melania had many ideas for improvements: she wanted to install a septic tank nearby, which she estimated would cost hundreds of dollars. She also wanted to install a pump that would transport water from a nearby stream uphill to the pig pen. To protect her pig from the heat, Melania also wished to buy metal sheeting to form a pig pen roof, which would cost approximately $\$ 90$. This would serve as a temporary solution until Ariel could spare the money and time necessary to make a higher quality palm frond roof.

During later questioning, Melania described her plans to expand the pig pen to fit the current adult male pig and two piglets that would soon be given to Melania as payment in a breeding agreement. The team was surprised by this, as the pen had seemed large enough to fit the male pig and multiple piglets. Further questioning prompted Melania to revise her original statement and concede that the current pen was spacious enough to accommodate three adult pigs. During another discussion, the team asked whether there were other pigs in the community with which to breed. Melania responded that she did not know. Her son, who sat in on each meeting, stepped in and made it clear there were other male and female adult pigs nearby, as there were three other pig farms within and near the community.

Throughout their discussions, the team continued to question Melania about every aspect of her business. At one point, Melania asked why the students had so many questions. She asked if they meant to take her information and begin a pig farm in the United States. The students did their best to explain through Kevin that they needed the information in order to give Melania accurate

52 NEW ENGLAND JOURNAL OF ENTREPRENEURSHIP 
recommendations for her pig farm. They thought she must understand their intentions, as she had previously worked with another GBB team and had been briefed by GBB before their arrival. Upon hearing their assurances, Melania cautiously agreed to proceed.

Throughout the week, the team responsible for Cría de Melania continued to meet with Melania every afternoon after the morning workshops had concluded. Each day, the group traveled three hours in a cramped van to get from their hostel to the village and back. Each evening they used this information to devise their plan. The students worked 16-hour days preparing the financial literacy workshops, working with villagers, and brainstorming business development solutions.

By their final morning, the exhausted students believed they had developed a plan that could help Melania attain her goals. But they also had a devastating epiphany: getting Melania to implement the plan would be even more challenging than creating it. All their work could come to nothing. As the students reflected on the week, they realized that they had never developed Melania's trust, making it almost a forgone conclusion that she would never follow their suggestions.

Realizing the problem, the students took many steps to repair the relationship. To develop better rapport, they bought Melania a \$15 tarp that could serve as a temporary pig pen roof and provide shade for her pig. They worked hand in hand with the family to put up the tarp. The students also made sure to follow cultural norms, such as waiting until being "invited" before entering Melania's house and taking off their shoes once inside. Also, before presenting their recommendations, they talked to Melania about her culture and her grandchildren, both of which she was immensely proud. The students then shared information about their lives. Before the last day, Melania had worn an almost perpetual scowl. But on the last day, she was often smiling. The team realized it was much more likely that Melania would consider following their suggestions.

\section{Discussion: Application of the Trust Model to the Social Entrepreneurship Initiative}

The model of trust developed by Sheppard and Sherman (1998) is valued by entrepreneurship literature because it conceptualizes trust in two dimensions: relational form and relational depth (Ferguson, Schattke, \& Paulin, 2016; Ulhøi, 2005). An application of this multidimensional model of trust to the various relationships in the Global
Brigades case illustrates how trust and interparty relationships play a significant role in the effectiveness of social entrepreneurship initiatives. For instance, the relationship between Ipeti Emberá and the Panamanian government can be characterized as deep dependence. The villagers did not trust their government due to the neglect they experienced. The lack of trust in this relationship forced them to seek assistance from an external party, Global Brigades.

The relationship between Ipeti Emberá and Global Brigades can be characterized as deep interdependence. The villagers and Global Brigades established trust in their relationship that enabled them to avoid the risk of misanticipation. In this relationship, each party understood and identified with the other. This led to coordinated, effective, and successful initiatives that improved the quality of life in the village and allowed Global Brigades efforts to be fruitful. If Global Brigades had not trusted the villagers, it would not have invested resources in this particular community. Similarly, if the villagers had not trusted Global Brigades, they would not have agreed to spend the time and effort necessary to participate in the GBB initiatives.

The relationship between the villagers and the author's team can be characterized as shallow interdependence. The team established trust with their financial literacy workshop, which led to more effective lessons and successful application of the lessons to the villagers'lives. However, the authors'team almost did not establish trust in their relationship with Melania, which not only would have prevented their brigade from being successful, but also would have precluded Melania from implementing advice that could possibly increase the profitability of her pig farm and, consequently, the quality of her life.

\section{Strategies of Cultivating and Maintaining Deep Dependence}

Sheppard and Sherman (1998) indicate that the relationship between a government and its citizens can often be characterized as deep dependence. As mentioned previously, one of the risks associated with deep dependence relationships is neglect. This risk is realized in the relationship between Ipeti Emberá and the Panamanian government due to the government's significant lack of involvement. On a broad scale, the government has failed to decrease the prejudice against indigenous populations. It has also been ineffective in mitigating poverty or inequality, and has failed to provide opportunities for indigenous individuals to escape poverty. Concerning Ipeti 
Emberá specifically, the lack of attention given to indigenous students who struggle in school and the neglect of the region's infrastructure demonstrate the government's lack of support. This neglect, as well as broken promises such as the agricultural experts example, has prevented the Ipeti Emberá villagers from trusting the government. Sheppard and Sherman (1998) state that a sense of obligation is the appropriate mechanism with which to produce trust in deep dependence relationships. However, a lack of this sense of obligation, which is likely compounded by the cultural differences, prevents trust from being established between these two parties. As a result, the villagers attempted to solve their problems without assistance from individuals or institutions outside of the village. An inability to do this contributed to the community's financial, educational, and other deficiencies. Consequently, the villagers require help from a trustworthy outside party: Global Brigades.

\section{Strategies of Cultivating and Maintaining Deep Interdependence}

An analysis of Sheppard and Sherman's (1998) model reveals that the relationship between Ipeti Emberá and Global Brigades can be categorized as deep interdependence. Ipeti Emberá depends on Global Brigades for assistance that is not provided by the Panamanian government. Global Brigades depends on the villagers for insight into their problems and cooperation in Global Brigades initiatives.

As discussed above, Sheppard and Sherman (1998) state that the main risk associated with deep interdependence is misanticipation: the risk that, without detailed instructions, one party will be unable to anticipate the needs or actions of the other party. The appropriate trust production mechanism in a deep interdependence relationship is internalization (Sheppard \& Sherman, 1998). Time, proximity, shared strategizing, shared identity, common incentives, and the negotiation of common values are all important facilitators of internalization (Sheppard \& Sherman, 1998). Global Brigades and the community establish trust and mitigate the risk of misanticipation by utilizing many of these facilitators.

The first internalization facilitator used in this relationship is shared strategizing. As mentioned above, Global Brigades spends ample time evaluating and communicating with a community before initiating brigades. By strategizing with Ipeti Emberá leaders before beginning any initiatives, GBB ensured it held the same goals and expectations as the community members.
This was a crucial component of establishing trust and preventing misanticipation. Additionally, once a brigade is finished and the brigaders depart, Global Brigades limits communication between villagers and brigaders. This prevents brigaders from making promises that they may not keep and effectively ensures that only GBB and the villagers engage in strategizing. This policy is instrumental in limiting misanticipation and maintaining trust with community members.

The second and third internalization facilitators used in this relationship are time and proximity. The in-country Global Brigades staff communicates with villagers on a weekly basis. This consistent attention shows villagers that Global Brigades is dedicated and trustworthy. Additionally, because the Global Brigades staff is located in the same country as the community, they can physically visit the community on a regular basis, further enhancing the relationship between the community and Global Brigades. When brigades take place, the Global Brigades staff serves as translators and liaisons between villagers and brigaders, further developing trust through time and proximity.

The fourth internalization facilitator used in this relationship is negotiation of common values. This is a clear function of the financial literacy workshops, which are designed to teach financial literacy concepts to the members of Ipeti Emberá by using personalized, relevant discussions. Additionally, the negotiation of common values is exemplified by the Credit and Savings Cooperative. As mentioned above, the members of Ipeti Emberá are committed to their culture, and one aspect of this culture is spending money as soon as one earns it. However, GBB understands the importance of saving money and encourages community members to adopt this value. The generous interest rate for savings at the cooperative (1\% per month) represents GBB's attempt to convince the community members to embrace the organization's values regarding saving. Moreover, elected leaders of the Ipeti Emberá community manage the cooperative and community members are able to determine how the cooperative profits are used. This indicates that the community members are empowered to keep their own values through the same GBB initiative. In this way, the Credit and Savings cooperative illustrates the negotiation of shared values between GBB and the members of Ipeti Emberá. This negotiation allows GBB and villagers to adopt similar values, which increases trust between these two parties.

54 NEW ENGLAND JOURNAL OF ENTREPRENEURSHIP 


\section{Strategies of Cultivating and Maintaining Shallow Interdependence}

There were essentially two different relationships involving the authors' team, each of which can be characterized as shallow interdependence. The first relationship was between the authors' team and their financial literacy workshop group. The second relationship was between the authors' team and Melania.

The relationship between the authors' team and their financial literacy workshop group can be characterized by shallow interdependence. The team depended on the villagers to pay attention and apply the concepts presented to their own lives. If villagers did not do this, the team's time, money, and effort invested in the brigade would be in vain. The villagers depended on the team for good instruction that would improve their financial literacy, and thereby improve their quality of life. Sheppard and Sherman (1998) indicate that the appropriate trust production mechanism in a shallow interdependence relationship is "active discovery through communication and research."The two parties completed this active discovery throughout the financial literacy workshops. For example, the icebreaker that involved responding "yes" or "no" to statements of personal interests enabled each party to learn about and better understand the other. Additionally, when villagers participated in workshops by describing their financial experiences and situations, brigaders better understood villagers and were able to tailor their lessons so they were more useful. This was clearly illustrated by the woman who followed the financial workshop teachings to save money instead of purchasing a redundant hair clip. Her feedback encouraged both the brigaders and other villagers that the discovery from the workshop lesson was successful, and consequently created trust between the two parties. The "best friend" system also contributed to active discovery between villagers and brigaders. Discussions between best friends, facilitated by translators, encouraged a deeper level of discovery that created trust on a personal level.

The relationship between the authors' team and Melania can also be characterized by shallow interdependence. Team members depended on Melania to give them accurate information concerning her business, understand their suggestions, and implement the recommendations after the brigade ended. Melania relied on the team to give her good advice and to not misuse the information that she provided. This relationship is particularly interesting because trust was not established until the very end of the brigade.
Trust was initially elusive in this particular relationship for many reasons. As discussed above, the students committed many cultural gaffes, such as entering Melania's home without gaining permission, neglecting to remove their shoes in her home, beginning meetings with business instead of culturally acceptable social pleasantries, and inquiring about her ability to read without establishing any kind of rapport. Factors that were out of the team's control also likely contributed to the mistrust Melania felt toward the brigaders. These included Melania being in a different financial literacy workshop group and therefore not bonding with the students through icebreakers, being paired with a different "best friend," and having a mentor who refused GBB business consulting assistance.

As previously mentioned, the risks associated with a shallow interdependence relationship are unreliability, indiscretion, and poor coordination (Sheppard \& Sherman, 1998). All three of these risks were realized before the team was able to produce trust in the relationship. Unreliability is the risk that one party will not behave as expected (Sheppard \& Sherman, 1998). This occurred multiple times throughout the week as Melania withheld information from the brigaders. For example, Melania stated that she did not know if there were other pigs in the village. It is very unlikely that Melania truly did not know, considering the community has only 85 families, Melania had lived in this community her entire life, and her son readily knew the answer. Melania's tendency to withhold information was not malicious. She was clearly worried about the second risk of shallow interdependence relationships, indiscretion, in which one party will inappropriately utilize or disclose sensitive information (Sheppard \& Sherman, 1998). Melania's consideration of this risk was explicitly stated when she asked the team members if they were posing so many questions because they intended to use her information to begin a pig farm in the United States. The final risk associated with shallow interdependence relationships, poor coordination, is the risk that coordination will not be rapid or effective enough to be successful (Sheppard \& Sherman, 1998). This was the risk that brutally confronted the authors' team at the end of the week; the lack of trust in their relationship with Melania made the possibility that she would refuse to cooperate and ignore their suggestions very real. 
Team members utilized the trust production mechanism for shallow interdependence relationships, discovery through communication and research, to establish trust at the end of their brigade. First, the team improved their communication by beginning the final meeting by speaking with Melania about her family and culture, culturally appropriate topics and much appreciated by Melania. Second, the team showed that they had conducted sufficient research about Melania's culture by entering her home in the proper manner and removing their shoes once they were inside. Similarly, team members indicated that they had conducted sufficient research regarding Melania's business by responding to her express desires. When the students presented Melania with a recommendation, they told her the amount of money she could gain if she followed their recommendation. They then explained that this money could be used to further her grandchildren's education, which was very important to her. Additionally, the team responded to Melania's desire for additional shelter for her pig by buying the tarp and working with her family to erect it. This active discovery began to produce trust in the relationship, mitigating the risks of shallow interdependence and facilitating a successful outcome of the social entrepreneurship effort.

\section{The Absence of Shallow Dependence}

Even though this case study analyzes multiple relationships, it does not provide an example of shallow dependence, the fourth form of trust discussed by Sheppard and Sherman (1998). This gives a small indication of the relevance of shallow dependence relationships to social entrepreneurship. In general, social entrepreneurship initiatives are not conducive to shallow dependence relationships because each party is invested in the success of the initiative. Social entrepreneurs are motivated to begin initiatives because they seek social change, social impact, or social transformation (Ebrashi, 2013). Volunteers and employees who take part in social entrepreneurship efforts often have similar goals. Their desire to make a difference causes them to be invested in the outcome of their initiatives. Simultaneously, social entrepreneurship initiatives are typically designed to help or empower certain populations; members of these populations are inherently invested in the outcome of the initiatives. This shared investment makes one risk very pertinent: poor coordination. Poor coordination, as discussed earlier, is the risk that coordination will not be rapid or effective enough to be successful (Sheppard
\& Sherman, 1998). Coordination cannot be achieved without the participation and contribution of each party; consequently, both parties rely on each other to achieve the success of the initiative in which they are both invested. For this reason, it is very rare to find shallow dependence relationships in social entrepreneurship.

\section{Conclusion}

Sheppard and Sherman (1998) believe their model of trust can help users understand the form and depth of a relationship, and thereby manage the trust and associated risks within the relationship. In this article we argue that this model can also be used to understand the trust and associated risks of relationships within social entrepreneurship initiatives. Although we acknowledge the very narrow scope of our research, we are confident that our experience in Panama is not unique; we contend that trust is an essential component of social entrepreneurship success. Nevertheless, more research regarding trust and social entrepreneurship must be completed in order to provide broad conclusions that can be utilized by social entrepreneurs. It is our hope and conviction that better understanding and enhanced consideration of trust will enable social entrepreneurs to achieve greater effectiveness and increased social impact.

56 NEW ENGLAND JOURNAL OF ENTREPRENEURSHIP 


\section{ACKNOWLEDGMENT}

This research, in part, was funded by University of Michigan-Flint's Hagerman Center for Entrepreneurship and Innovation.

\section{REFERENCES}

Bogren, M., \& von Friedrichs, Y. (2016). Trust-building processes in women's entrepreneurship. Journal of Enterprising Communities, 10(1), 70-100.

Central Intelligence Agency. (2015). Panama. Retrieved October 13, 2015, from https://www.cia.gov/library/publications/ the-world-factbook/geos/pm.html

Curtis, T., Herbst, J., \& Gumkovska, M. (2010). The social economy of trust: Social entrepreneurship experiences in Poland. Social Enterprise Journal, 6(3), 194-209. http://dx.doi.org.huaryu.kl.oakland.edu/10.1108/17508611011088805

Ebrashi, R. E. (2013). Social entrepreneurship theory and sustainable social impact. Social Responsibility Journal, 9(2), 188-209. http://dx.doi.org.huaryu.kl.oakland.edu/10.1108/SRJ-07-2011-0013

Ferguson, R., Schattke, K., \& Paulin, M. (2016). The social context for value co-creations in an entrepreneurial network: Influence of interpersonal attraction, relational norms and partner trustworthiness. International Journal of Entrepreneurial Behaviour \& Research, 22(2), 199-214.

Fiske, A. P. (1990). Relativity within Moose culture: Four incommensurable models for social relationships. Ethos, 18, 180-204.

Global Brigades. (2014). A look at Global Brigades in Panama [Unpublished document].

Global Brigades. (2015a). History. Retrieved July 24, 2015, from https://www.globalbrigades.org/history

Global Brigades. (2015b). Home. Retrieved July 24, 2015, from https://www.globalbrigades.org/

Global Brigades. (2015c). Ipeti Embera, Panama. Retrieved July 24, 2015, from https://www.globalbrigades.org/panamacommunities-ipeti-embera

Global Brigades. (2015d). Mission and Vision. Retrieved July 24, 2015, from https://www.globalbrigades.org/mission-vision-new

Jiao, H. (2011). A conceptual model for social entrepreneurship directed toward social impact on society. Social Enterprise Journal, 7(2), 130-149. http://dx.doi.org/10.1108/175086111111156600

Mair, J., \& Marti, I. (2006). Social entrepreneurship research: A source of explanation, prediction, and delight. Journal of World Business, 41(1), 36-44.

Rousseau, D. M., Sitkin, S. B., Burt, R. S., \& Camerer, C. (1998). Not so different after all: A cross-discipline view of trust. Academy of Management Review, 23(3), 393-404.

Scheiber, L. A. (2014). Social capital and the target population. Social Enterprise Journal, 10(2), 121-134.

Sheppard, B. H., \& Sherman, D. M. (1998). The grammars of trust: A model and general implications. Academy of Management Review, 23(3), 422-437.

Ulhøi, J. P. (2005). The social dimensions of entrepreneurship. Technovation, 25(8), 939-946. http://doi.org.huaryu.kl.oakland. edu/10.1016/j.technovation.2004.02.003

Zhang, J., \& Hamilton, E. (2010). Entrepreneurship education for owner-managers: The process of trust building for an effective learning community. Journal of Small Business and Entrepreneurship, 23(2), 249-270, 307-308.

THE ROLE OF TRUST IN SOCIAL ENTREPRENEURSHIP 57 


\section{ABOUT THE AUTHORS}

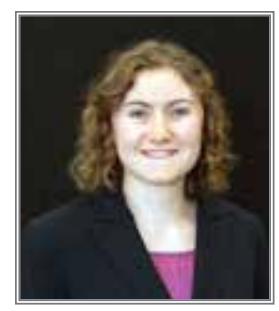

Laura Tack (letack@oakland.edu) received her B.S. from Oakland University, Michigan, with a concentration in Accounting. She is currently a student in the Master of Business Administration program at Oakland University.

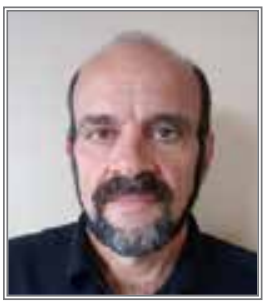

Mark Simon (marksimo@umflint.edu) is Hagerman Professor of Entrepreneurship and Innovation at the University of Michigan-Flint where he teaches entrepreneurship and is Director of the Hagerman Center for Entrepreneurship and Innovation. He received his B.S. from Babson College and shortly thereafter started an import company and an outdoor recreation business. He obtained an MBA and Ph.D. from Georgia State University. He has publications in the area of entrepreneurial decision making in multiple academic journals.

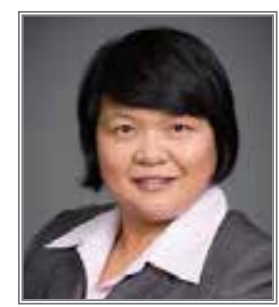

Ruihua Joy Jiang (jiang@oakland.edu) is an associate professor of management and international business at Oakland University. She received her Ph.D. in Strategic/International Management from Ivey School of Business, Western University, Canada. Her research focuses on cooperative strategy, internationalization strategy, and international entrepreneurship. 